\title{
EPT NO BRASIL: HISTÓRICO, PANORAMA E PERSPECTIVAS
}

\author{
Carlos Alberto Dallabona ${ }^{1}$ \\ Tharsila Maynardes Dallabona Fariniuk ${ }^{2}$
}

\section{RESUMO}

Este texto discute as tendências e possibilidades da Educação Profissional e Tecnológica - EPT no Brasil. Este componente do processo educacional tem oscilado entre políticas conflitantes entre si ao longo do tempo, implantadas e implementadas de maneiras distintas, decorrentes de disputas entre grupos de poder. A partir de dados quantitativos que compõem o cenário e de perspectivas desejáveis para o futuro, incluindo metas do Plano Nacional de Educação - PNE 2014-2024, apresentam-se possibilidades para esse segmento que, mesmo tendo significativo crescimento nos últimos anos, está muito aquém das necessidades do país. A ampliação, que precisa ocorrer tanto em termos quantitativos como qualitativos, deve partir da compreensão da evolução histórica, permitindo direcionar esforços para aproveitar efetivamente as experiências exitosas e o potencial de crescimento disponível, de forma sinérgica, sistêmica e institucionalizada.

Palavras-chave: Educação profissional; Educação Profissional e Tecnológica; Políticas públicas.

\section{EPT IN BRAZIL: HISTORY, PANORAMA AND PROSPECTS}

\begin{abstract}
This text discusses the trends and possibilities of Professional and Technological Education - PTE in Brazil. This component of the educational process has oscillated between conflicting policies over time, deployed and implemented in different ways, due to disputes between power groups. From quantitative data which compose the scenario and prospects desirable for the future, including goals of the National Education Plan - PNE (in Portuguese acronym) 2014-2024, possibilities for this segment are presented, which even having had significant growth in recent years, is still far the country's needs. The expansion, which must take place both in quantitative and qualitative terms, must starts from the understanding of the historical evolution, allowing direct efforts to effectively use of the successful experiences and the growth potential available, synergistically, systemically and institutionalized.
\end{abstract}

Keywords: Professional education; Professional and technological education; Public policies.

\section{EPT EN BRASIL : HISTORIA, PANORAMA Y PERSPECTIVAS}

\section{RESUMEN}

Este texto discute tendencias y posibilidades de la Educación Profesional y Tecnológica - EPT en Brasil. Este componente del proceso de educación tiene oscilado entre políticas conflictivas entre sí a lo largo del tiempo, implantadas e implementadas de maneras distintas, decurrentes de disputas entre grupos de poder. Desde datos cuantitativos que componen el escenario y de perspectivas

\footnotetext{
1 Engenheiro eletricista, mestre em engenharia de produção pela UFSC, doutor em educação pela UDELMAR (Chile) e Professor da UTFPR. Coordenador adjunto da Rede eTec Brasil na UTFPR. E-mail: <dallabona@utfpr.edu.br>

2 Arquiteta e Urbanista, mestre em Gestão Urbana pela PUCPR e Doutoranda em Gestão Urbana pela PUCPR. Membro da equipe do Curso Técnico em Logística EaD UTFPR. E-mail: <tharsilamd@hotmail.com>
} 
deseables para el futuro, incluyendo metas del Plan Nacional de Educación - PNE 2014-2024, se presentan posibilidades para ese segmento que, aunque ha tenido significativo crecimiento en los últimos años, aún se quedan lejos de las necesidades del país. La ampliación, que precisa ocurrir en términos cuantitativos y cualitativos, debe partir de la comprensión de la evolución histórica, permitiendo direccionar esfuerzos para aprovechar efectivamente las experiencias exitosas y el potencial de crecimiento disponible, de manera sinérgica, sistémica e institucionalizada.

Palabras-clave: Educación profesional; Educación Profesional y Tecnológica; Políticas públicas.

\section{INTRODUÇÃO}

A educação profissional e tecnológica - EPT, no sentido estabelecido pela legislação brasileira atual, inclui os cursos de nível médio e pós-médio direcionados a preparação para o trabalho, sejam eles do tipo integrado (inclui formação profissional e Ensino Médio em curso único), concomitante (cursos distintos ao mesmo tempo), ou subsequente (formação profissional após conclusão do Ensino Médio), bem como cursos superiores de tecnologia e cursos de formação inicial.

No Brasil, este tipo específico de educação tem sido objeto de ações ao longo da história, especialmente a partir do início do século XX. A tipologia chegou a ser um modelo de referência a ser disseminado como solução obrigatória para o desenvolvimento do país. No entanto, a abordagem tem sido conflitante ao longo do tempo, em termos de integração ou separação do sistema geral de ensino. Em tempos recentes, este tipo de educação tem tido atenção e recebido investimentos significativos, principalmente no nível de formação técnica profissional, destacando-se a implantação da Rede Federal EPT e programas específicos de incentivo e fomento.

Este texto origina-se da consideração de que se faz necessário a ampliação da EPT no Brasil, a partir de políticas públicas implementadas de forma coerente, incluindo as modalidades presencial e a distância, e envolvendo instituições públicas e privadas.

O presente texto tem por objetivo apresentar o cenário atual da EPT no Brasil, a partir do questionamento da complexidade do desafio quantitativo e dos requisitos qualitativos a serem alcançados.

Para o cumprimento deste objetivo, foi realizada uma análise quantitativa com base documental, partindo de planilhas estatísticas disponibilizadas online pelo Instituto Nacional de Estudos e Pesquisas Anísio Teixeira - INEP, e dados de documentos sobre o Plano Nacional de Educação - PNE 2014-2024. A análise foi realizada com base em conjunto 
de dados composto pelos documentos do PNE e pelo número de matrículas recentes nos cursos EPT. Os dados coletados consideram cursos técnicos (integrado, concomitante e subsequente) e cursos de tecnologia. O recorte temporal adotado é o período de 2008 a 2015, uma vez que, nestes anos, há dados disponíveis referentes a matrículas.

A análise foi realizada no sentido de contextualizar, primeiramente, a evolução do número de matrículas por tipologia de cursos. Em seguida foram considerados dados e metas do PNE que serviram de base comparativa e, por fim, foi realizada a verificação de aproximações e discrepâncias entre as metas e os resultados obtidos até o momento, indicando perspectivas de evolução da EPT.

O texto está estruturado de modo a apresentar, primeiramente, o contexto da EPT no Brasil e conceitos relacionados. Na sequência são apresentados os resultados, a discussão e as considerações finais.

\section{CONTEXTO DA EDUCAÇÃO PROFISSIONAL E TECNOLÓGICA NO BRASIL}

$\mathrm{Na}$ história da educação brasileira, uma questão recorrente nos debates diz respeito à formação acadêmica versus formação para o trabalho. A primeira é representada pelos estudos tradicionais ofertados pelo sistema de ensino, identificada por termos como acadêmica e propedêutica. A segunda é representada por um tipo de ensino destinado a formar para o trabalho, indicada pelo termo profissional e variações. O conflito entre as duas modalidades marcou principalmente o ensino de nível técnico ao longo do tempo, e continua presente no cenário educacional brasileiro.

A EPT inclui cursos de formação inicial e continuada, desvinculados do sistema regular de ensino, destinados à formação profissional básica, cursos técnicos que se situam no mesmo nível dos cursos de nível médio; e cursos de tecnologia, estes situados no âmbito da Educação Superior. A educação profissional diferencia-se tanto da educação formal como da não formal, constituindo uma terceira via no processo de desenvolvimento da pessoa. A partir da base de conhecimento, habilidades, competências, valores e atitudes préexistentes, a pessoa estabelece correspondências ligadas a uma ampliação da perspectiva de sua atuação profissional (RAMÍREZ, 2002). 
O termo ensino profissional, conforme esclarece Nascimento (2007), deriva do contexto que considerava duas ideias diferentes de ensino. Uma delas referia-se à educação formal e sistemática que, a partir da Idade Média, deu origem aos colégios e universidades atuais. A outra ideia referia-se a um tipo de ensino progressivo e não sistemático, ou pouco sistemático, destinado à aprendizagem de ofícios, através de mestres e aprendizes, e da qual deriva o que pode ser chamado de ensino profissional que, mais tarde, passou a incluir, além do ensino de ofícios, também o ensino industrial, destinado ao aprendizado das técnicas e tecnologias utilizadas nos processos industriais. Estas ideias estão presentes, de forma conflitante ou complementar, na história das instituições de ensino profissional brasileiras, cuja trajetória salienta a separação entre ensino regular e ensino profissional, com discussões, conflitos e alguns esforços de convergência.

Originalmente, a expressão Educação Profissional constava no artigo 39 da LDBE

- Lei de Diretrizes e Bases da Educação Nacional de 1996, que foi integralmente alterado pela Lei 11.741 de 16 de julho de 2008, a qual incluiu a denominação Educação Profissional e Tecnológica e a integração a outros níveis e modalidades da educação (BRASIL, 2008):

Art. 39. A educação profissional e tecnológica, no cumprimento dos objetivos da educação nacional, integra-se aos diferentes níveis e modalidades de educação e às dimensões do trabalho, da ciência e da tecnologia.

$\S 1^{\text {oos }}$ cursos de educação profissional e tecnológica poderão ser organizados por eixos tecnológicos, possibilitando a construção de diferentes itinerários formativos, observadas as normas do respectivo sistema e nível de ensino.

$\S 2$ 2A educação profissional e tecnológica abrangerá os seguintes cursos:

I - de formação inicial e continuada ou qualificação profissional;

II - de educação profissional técnica de nível médio;

III - de educação profissional tecnológica de graduação e pós-graduação.

$\S 3^{\circ}$ Os cursos de educação profissional tecnológica de graduação e pósgraduação organizar-se-ão, no que concerne a objetivos, características e duração, de acordo com as diretrizes curriculares nacionais estabelecidas pelo Conselho Nacional de Educação.

Assim, o termo deriva da chamada educação profissional, que era usual para designar, de forma genérica, os cursos técnicos e também outros cursos preparatórios para o trabalho, inseridos ou não no sistema geral de educação e agrega o termo tecnológica para incluir cursos de graduação, genericamente denominados sob o título de tecnologias, cursos em geral de menor duração do que os bacharelados e licenciaturas, com características 
próximas aos cursos de formação profissional. No Brasil, os cursos EPT são ofertados nos sistemas público e privado, além de instituições voltadas prioritariamente para esse fim, que são o Sistema S e a Rede Federal de Educação Profissional e Tecnológica (sistema público).

O Sistema S diferencia-se por ter sido criado por lei e mantido por instituições do setor privado, do qual fazem parte o Serviço Nacional de Aprendizagem Industrial - SENAI, o Serviço Nacional de Aprendizagem Comercial - SENAC e outros. Esse sistema oferta cursos de formação nas respectivas áreas de atuação das entidades, desvinculados do sistema formal de ensino. Foi oficialmente criado em 1942 (BRASIL, 1942), quando de uma das reformas do sistema de ensino no país, sendo a proposta básica estabelecer que o sistema produtivo assumisse a formação profissional dos filhos dos operários do setor.

A Rede Federal de Educação Profissional e Tecnológica, por sua vez, inclui as instituições que ofertam cursos técnicos profissionalizantes e cursos de graduação de tecnologia tendo, assim, uma atuação no nível médio e no nível superior de formação. Esta rede é composta pelos Institutos Federais - IF, Centros Federais de Educação Tecnológica CEFET, Escolas técnicas vinculadas a Universidades Federais - ET UF, pela Universidade Tecnológica Federal do Paraná - UTFPR e pelo Colégio Pedro II.

O modelo atual para os cursos técnicos permite diversos matizes, desde o modelo integrado, que reúne o Ensino Médio com o profissional; passando por modelos híbridos, como o curso subsequente, que confere formação profissional a egressos do Ensino Médio; e o modelo concomitante, que inclui Ensino Médio e profissional em cursos distintos, porém simultâneos. Os cursos do tipo subsequente, embora classificados como parte do Ensino Médio, situam-se entre o médio e o superior. Na classificação internacional da UNESCO, este tipo de curso corresponde ao nível IV (UNESCO, 2016).

\subsection{HISTÓRICO}

O contexto no qual se insere a educação profissional no Brasil decorre de uma cultura pela qual o domínio dos conteúdos gerais das ciências, letras e humanidades eram considerados os únicos reconhecidos e válidos para a formação dos dirigentes e, portanto, uma formação reservada a uma elite. O ensino profissional era entendido como formação instrumental e não permitia acesso ao Ensino Superior, a não ser através de exames de 
adaptação que, na prática, implicavam em demonstrar conhecimento dos conteúdos do ensino humanista (KUENZER, 2007). Essa cultura tem seus primórdios na separação entre teoria e prática, presente na filosofia grega que diferenciava Technê e Epísteme. Esse contraste está na base da dicotomia entre ciência e tecnologia, e da disputa entre ambas (STANFORD, 2003). O termo Technê indica uma capacidade de produzir algum objeto por meios racionais, estando relacionada com artesanato ou arte. Desta ideia origina-se, também, o termo tecnologia, incluindo objetos realizados a partir da criatividade, conhecimento, prática e experimentação. Por sua vez, Epísteme indica conhecimento em estado puro, que pode ser atualizado como ciência.

Considerando processos sistemáticos de ensino-aprendizagem de atividades do tipo manufatureiro e industrial, o Brasil teve um desenvolvimento tardio decorrente de questões culturais e políticas, situando-se mais propriamente a partir do início do século XX. Nos anos 40, transformações relevantes ocorreram na educação profissional brasileira, como a Reforma Capanema, que transformou os Liceus Industriais em Escolas Técnicas e a criação do SENAI (BRASIL, 1942; CUNHA, 2000). Em 1961, a primeira Lei de Diretrizes e Bases da Educação, Lei 4.024 (BRASIL, 1961), que estava prevista desde a constituição de 1934, estruturou o sistema educacional em: Ensino Primário; Ensino de grau Médio e Educação de grau Superior, sendo o ensino de grau médio dividido em: 10 ciclo - ginasial e de 20 ciclo colegial (curso secundário, curso técnico e curso de formação de professores para o ensino primário e pré-primário). No que diz respeito ao ensino profissional, permitiu que as escolas ofertassem cursos do tipo técnico integrado com o ensino secundário, o que se tornou, nos anos seguintes, um modelo de sucesso e que serviu de referência para uma posterior reforma do ensino secundário geral. Outro fator que se revelou fundamental para o sucesso dos cursos técnicos foi o acesso aos cursos superiores após o terceiro ano, o que permitiu uma forma efetiva de transição do sistema de ensino profissional para o superior. Esses novos cursos, ofertados pelas Escolas Técnicas Federais, logo conquistaram um prestígio profissional relevante, sendo os egressos disputados pelo mercado pela excelência de sua formação, e passaram a representar uma possibilidade real e efetiva de ascensão econômica e social para os formados. A qualidade dos cursos passou a atrair, nas décadas seguintes, também estudantes de boa situação econômica, que antes se dirigiam ao ensino secundário geral e deles aos cursos superiores. 
Em 1997, o Decreto 2.208 de 17 de abril de 1997 (BRASIL, 1997) proibiu cursos de tipo técnico integrado ao Ensino Médio, e estabeleceu a separação entre Ensino Médio e educação profissional, fazendo com que as instituições ofertantes de educação profissional deixassem a dupla missão de oferta propedêutica e profissionalizante (PEREIRA; PASSOS, 2011). Este decreto foi bastante criticado por restabelecer o dualismo entre educação e trabalho, o que contradiz os princípios da politecnia (FRIGOTTO; CIAVATTA; RAMOS, 2005). A situação perdurou até 2004, quando o Decreto 5.154 de 21 de julho de 2004 que, retomando parcialmente a estratégia política usada em 1942 para permitir tanto a integração como a separação entre educação geral e profissional, permitiu o retorno dos cursos do tipo integrado, mantendo os cursos concomitante e subsequente (BRASIL, 2004).

Em anos recentes foram criados os Institutos Federais de Educação pela Lei 11.892 de 29 de dezembro de 2008 (BRASIL, 2008), a mesma que formalizou a Rede Federal EPT, especializada na oferta de cursos profissionais e tecnológicos. Outra ação relevante foi a criação da Escola Técnica Aberta do Brasil - eTec Brasil, pelo Decreto 6.301 de 12 de dezembro de 2007 (BRASIL, 2007), com o objetivo de ofertar cursos técnicos subsequente a distância, pela Rede Federal EPT e instituições estaduais. Este programa foi transformado em Rede eTec Brasil pelo Decreto 7.589 de 26 de outubro de 2011 (BRASIL, 2011), que inseriu no programa a possibilidade de participação do Sistema S e oferta de cursos de tecnologia, sendo que esta modalidade não foi ofertada no âmbito do programa até a redação deste texto.

\section{RESULTADOS: CENÁRIO ATUAL DA EPT NO BRASIL}

Dados quantitativos para compor o cenário da EPT no Brasil são disponibilizados principalmente pelo INEP através de censos e sinopses da educação, estas publicadas anualmente e que constituem material de referência necessária pelo seu caráter de oficialidade, embora os dados requeiram interpretação cuidadosa. Um exemplo dos cuidados necessários é que, nas sinopses estatísticas, a coluna indicada como sendo o total pode não corresponder à soma das colunas a sua direita, que usualmente são os componentes desse total. Também a totalização e agrupamento de dados têm diferenças, ocorrendo total diferente para um mesmo item em diferentes quadros. Esta situação é mais 
crítica nas sinopses da Educação Básica e menos comuns naquelas que dizem respeito à Educação Superior.

\subsection{SINOPSES ESTATÍSTICAS - CURSOS TÉCNICOS DE NÍVEL MÉDIO}

A legislação separa, na educação fundamental, o que é chamado de Ensino regular da Educação de Jovens e Adultos - EJA e da Educação Profissional. Decorrente desta abordagem, este texto mantém a separação. Até a mais recente sinopse disponível, não há dados sobre educação a distância, o que não permite diferenciar as modalidades a partir dessa fonte de referência. Também cursos de formação inicial e continuada - FIC não são incluídos, por serem de curta duração e não fazerem parte dos cursos regulares.

O quadro 1 indica que a EPT representa menos de $4 \%$ das matrículas totais na educação fundamental. Compondo a participação da educação profissional no total do Ensino Médio, esta representa 20,16\% das 9,5 milhões de matrículas nesse nível.

Quadro 1 - Matrículas na Educação Fundamental em 2015

\begin{tabular}{|c|c|c|}
\hline Educação infantil & 7.972 .230 & $16,3 \%$ \\
\hline Ensino fundamental & 27.931 .210 & $57,2 \%$ \\
\hline Ensino médio & 7.590 .465 & $15,6 \%$ \\
\hline Educação profissional & 1.917 .192 & $3,9 \%$ \\
\hline EJA & 3.385 .415 & $6,9 \%$ \\
\hline Total & 48.796 .512 & $100,0 \%$ \\
\hline
\end{tabular}

Fonte: Compilado pelos autores a partir da Sinopse Estatística (INEP, 2015).

O detalhamento das matrículas nos cursos incluídos como do grupo Educação Profissional na Sinopse da Educação Básica, representados no Gráfico 1, indica maioria de cursos técnico subsequente, que representam $53,4 \%$ do total, seguido pelos cursos técnico integrado (20.4\%) e concomitante (14,5\%). 


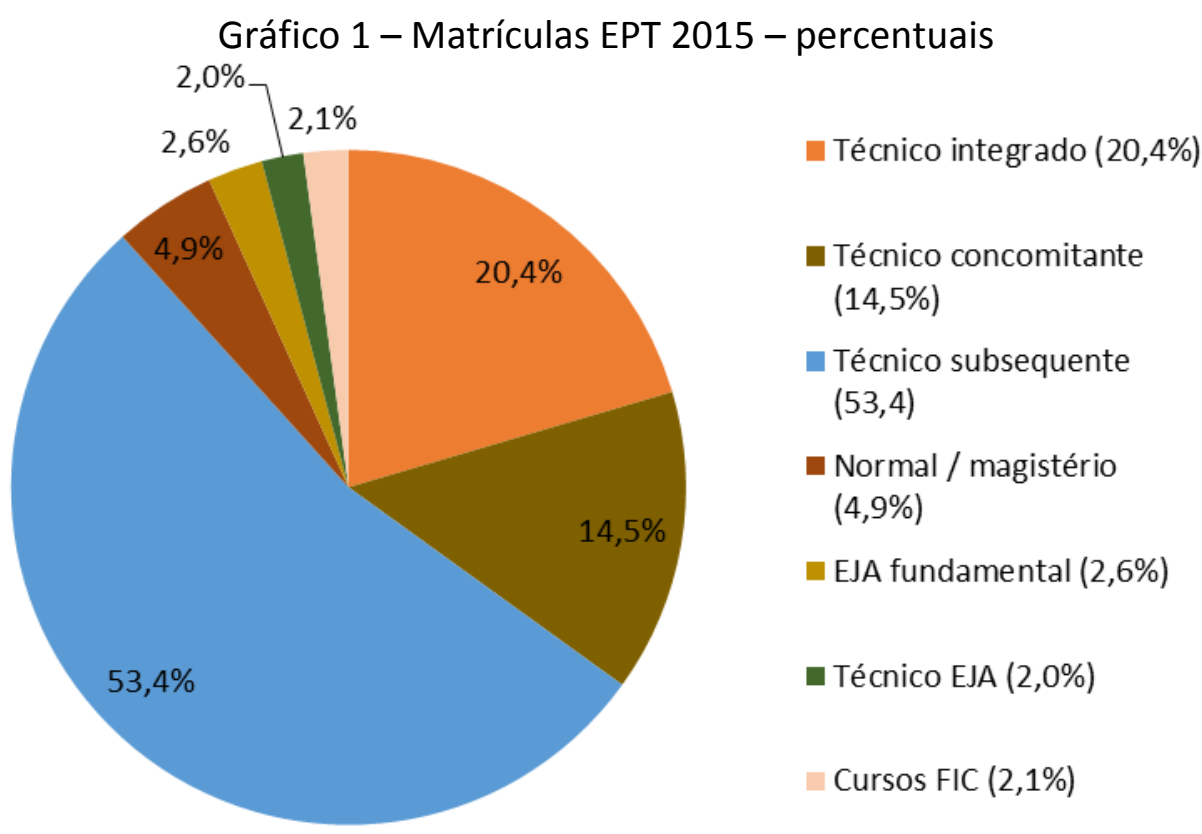

Fonte: Compilado pelos autores a partir da Sinopse Estatística (INEP, 2015).

O quadro 2 apresenta as matrículas dos cursos técnicos por tipo e categoria administrativa em percentuais, o que mostra que os cursos integrados são ofertados majoritariamente pela rede pública estadual e federal, enquanto os cursos concomitante e subsequente têm maioria de matrículas no sistema privado. Observa-se, também, que os municípios têm participação muito pequena nesse tipo de oferta.

Quadro 2 - Matrículas em cursos técnicos em 2015 - Percentual

\begin{tabular}{|c|c|c|c|c|}
\hline & Integrado & Concomitante & Subsequente & Total \\
\hline Federal & $34,1 \%$ & $10,6 \%$ & $14,9 \%$ & $18,6 \%$ \\
\hline Estadual & $57,4 \%$ & $21,8 \%$ & $22,6 \%$ & $30,5 \%$ \\
\hline Municipal & $2,5 \%$ & $1,4 \%$ & $1,2 \%$ & $1,5 \%$ \\
\hline Total público & $94,0 \%$ & $33,8 \%$ & $38,6 \%$ & $50,6 \%$ \\
\hline Privada & $6,0 \%$ & $66,2 \%$ & $61,4 \%$ & $49,4 \%$ \\
\hline Total & $100,0 \%$ & $100,0 \%$ & $100,0 \%$ & $100,0 \%$ \\
\hline
\end{tabular}

Fonte: Compilado pelos autores a partir da Sinopse Estatística (INEP, 2015).

O gráfico 2 apresenta uma série histórica de matrículas focando cursos técnicos de nível médio, e mostra que os cursos integrados e subsequentes apresentam crescimento significativo no período. No tipo subsequente passam de pouco mais de 400 mil matrículas para mais de 1 milhão em 2015, representando, nesse ano, mais da metade do total da categoria. 
Gráfico 2 - Evolução de matrículas em cursos técnicos - 2008 a 2015

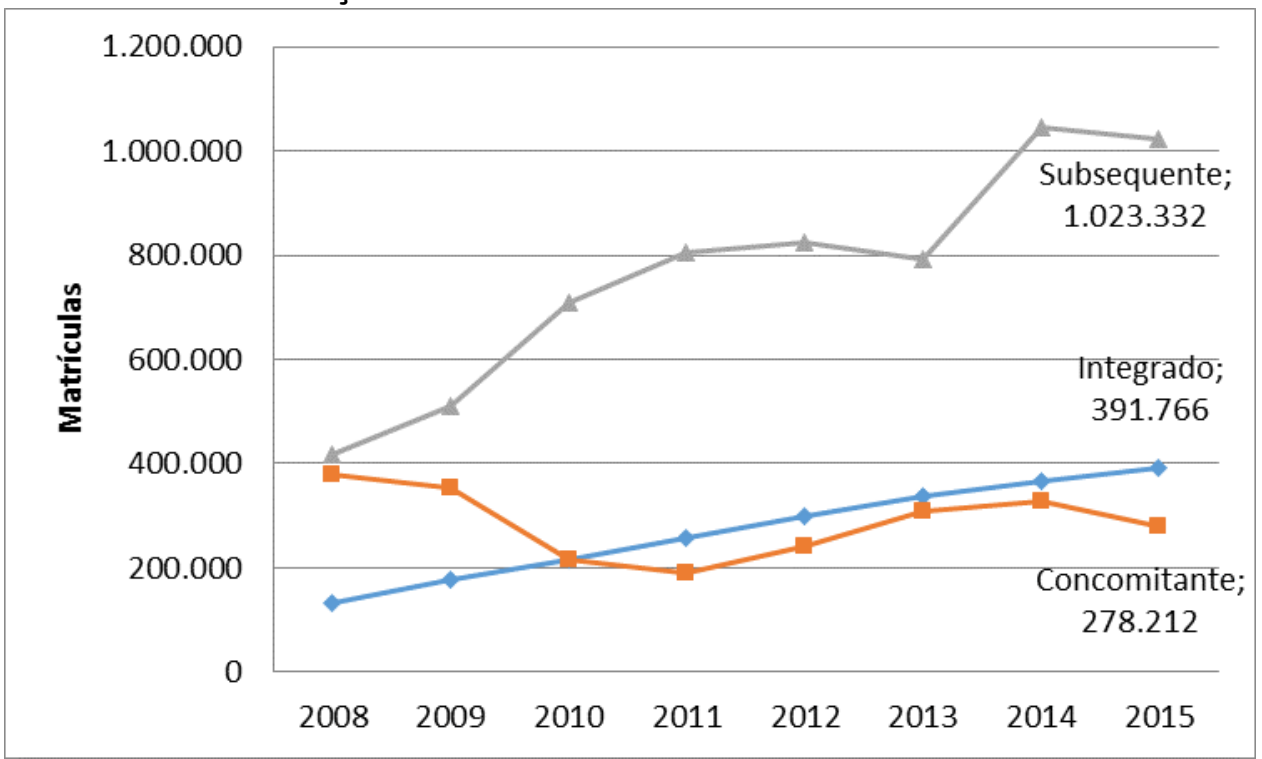

Fonte: Compilado pelos autores a partir das Sinopses Estatísticas (INEP, 2008; 2009; 2010; 2011; 2012; 2013; 2014a; 2015).

O gráfico 2 ressalta, também, os cursos integrados, que tinham cerca de 130 mil matrículas em 2008, e chegam próximo de 400 mil em 2015. Os cursos concomitantes têm tido oscilações, com fases de redução e ampliação de matrículas, chegando, em 2015, com um quantitativo de matrículas inferior ao que tinham em 2008. Estes fatos recomendam centrar a atenção de ampliação nos cursos integrado e subsequente.

Um fator relevante diz respeito à faixa etária dos estudantes matriculados nos cursos de formação profissional de nível médio, conforme o quadro 3, mostrando que 55,4\% dos matriculados está acima de 18 anos, ou seja, além da faixa etária de referência para o Ensino Médio. Isto concorda com a ampliação dos cursos subsequentes que, requerendo o Ensino Médio concluído, têm média de idade mais elevada.

Quadro 3-Cursos técnicos - Distribuição por faixa etária

\begin{tabular}{|c|c|c|}
\hline Até 14 anos & 45.175 & $2,4 \%$ \\
\hline 15 a 17 anos & 528.048 & $27,5 \%$ \\
\hline 18 a 19 anos & 282.176 & $14,7 \%$ \\
\hline 20 a 24 anos & 385.817 & $20,1 \%$ \\
\hline 25 anos ou mais & 675.976 & $35,3 \%$ \\
\hline
\end{tabular}

Fonte: Compilado pelos autores a partir da Sinopse Estatística (INEP, 2015). 
Considerando as carências educacionais crônicas no Brasil, o cenário indica como caminho natural a ampliação das matrículas dos cursos integrado, visando a buscar atendimento pleno da demanda. Como há demanda reprimida, a ampliação da oferta de cursos subsequentes é, também, necessária enquanto perdurar a escassez de vagas e dificuldades de acesso e conclusão nos cursos integrados, podendo, posteriormente, ser adequada às necessidades de formação continuada para os que fizeram Ensino Médio propedêutico e que desejam ampliar sua formação na área técnica. Assim, a ampliação de vagas nos cursos subsequentes seria temporária e haveria posterior redução.

\subsection{CURSOS DE GRADUAÇÃO}

O quadro 4 apresenta as matrículas em cursos de graduação no ano de 2014, última sinopse disponível quando da redação deste texto, por organização acadêmica (universidades, centros universitários, faculdades e IF/CEFET) e por grau acadêmico (bacharelado, licenciatura e tecnologia). Este quadro refere-se a cursos presenciais. Embora a sinopse apresente um quadro para cursos a distância, não traz os dados por nível acadêmico.

Quadro 4 - Matrículas em cursos de graduação - 2014 - Cursos presenciais

\begin{tabular}{|c|c|c|c|c|c|}
\hline & Universidades & $\begin{array}{c}\text { Centros } \\
\text { Universitários }\end{array}$ & Faculdades & $\begin{array}{c}\text { Institutos Federais / } \\
\text { CEFET }\end{array}$ & Total \\
\hline \multirow{2}{*}{ Bacharelados } & 2.429 .774 & 772.455 & 1.649 .336 & 41.342 & 4.892 .907 \\
& $(37,6 \%)$ & $(12,0 \%)$ & $(25,5 \%)$ & $(0,6 \%)$ & $(75,4 \%)$ \\
\hline \multirow{2}{*}{ Licenciaturas } & 562.700 & 71.195 & 254.075 & 37.972 & 925.942 \\
& $(8,7 \%)$ & $(1,1 \%)$ & $(3,9 \%)$ & $(0,6 \%)$ & $(14,3 \%)$ \\
\hline \multirow{2}{*}{ Tecnologias } & 190.790 & 120.108 & 290.512 & 43.715 & 645.125 \\
& $(3,0 \%)$ & $(1,9 \%)$ & $(4,5 \%)$ & $(0,7 \%)$ & $(10,0 \%)$ \\
\hline \multirow{2}{*}{ Total } & 3.183 .264 & 963.758 & 2.193 .923 & 123.029 & 6.463 .974 \\
& $(49,2 \%)$ & $(14,9 \%)$ & $(33,9 \%)$ & $(1,9 \%)$ & $(100, .0 \%)$ \\
\hline
\end{tabular}

Fonte: Compilado pelos autores a partir da Sinopse Estatística (INEP, 2014b).

O quadro 4 permite destacar que os bacharelados representam mais de três quartos do total de matrículas nos cursos de graduação presenciais, enquanto as tecnologias representam somente $10 \%$. Este tipo de curso, que faz parte da EPT, representa a maioria de matrículas nos Institutos Federais e CEFET, entidades que têm prioridade nesse tipo de cursos. A série história apresentada no Censo da Educação Superior 2013 (MEC.INEP, 2013) indica que os cursos de tecnologia tiveram aumento de $24,5 \%$ no período de 2010 a 2013 , 
enquanto, para os bacharelados, este aumento foi de 7,9\%. As licenciaturas ficaram praticamente estáveis no período, incluindo cursos presenciais e a distância. Em termos de matrícula, o maior aumento no período foi, também, dos cursos de tecnologia, com ampliação de $27,4 \%$ contra $1,6 \%$ nos bacharelados e 1,4\% nas licenciaturas. As diferenças entre aumento de cursos e de matrículas indica que vem ocorrendo ampliação da quantidade de vagas por curso.

O quadro 5 apresenta a distribuição de matrículas por organização acadêmica e categoria administrativa, mostrando grande concentração das instituições privadas nas matrículas nos centros universitários e faculdades, e no total. Nas universidades existe, ainda, uma situação de relativo equilíbrio entre matrículas públicas e privadas $(48,3 \%$ a $51,7 \%)$.

Quadro 5 - Matrículas em cursos de graduação presenciais - 2014 - Percentual

\begin{tabular}{|c|c|c|c|c|c|}
\hline & Universidades & Centros Universitários & Faculdades & Institutos Federais / CEFET & Total \\
\hline Federal & $29,9 \%$ & $0,0 \%$ & $0,1 \%$ & $100,0 \%$ & $16,7 \%$ \\
\hline Estadual & $15,8 \%$ & $0,2 \%$ & $3,1 \%$ & $0,0 \%$ & $8,9 \%$ \\
\hline Municipal & $2,6 \%$ & $2,6 \%$ & $2,4 \%$ & $0,0 \%$ & $2,5 \%$ \\
\hline Total público & $48,3 \%$ & $2,8 \%$ & $5,6 \%$ & $100,0 \%$ & $28,1 \%$ \\
\hline Privada & $51,7 \%$ & $97,2 \%$ & $94,4 \%$ & $0,0 \%$ & $71,9 \%$ \\
\hline Total & $100,0 \%$ & $100,0 \%$ & $100,0 \%$ & $100,0 \%$ & $100,0 \%$ \\
\hline
\end{tabular}

Fonte: Compilado pelos autores a partir da Sinopse Estatística (INEP, 2014b).

O cenário indica que a Rede Federal EPT deve ser incentivada a ampliar a oferta de seus cursos e sua participação no cenário educacional brasileiro, em paralelo com incentivos para que outras instituições, públicas e privadas, possam ampliar a oferta de cursos de tecnologia.

\section{3 . CONSIDERAÇÕES RELATIVAS AO PNE 2014-2024}

O PNE 2014-2024 (BRASIL, 2014) representa a terceira versão desse plano, que pretende ser um documento de referência da política educacional, apresentando princípios, diretrizes, prioridades, metas e estratégias de ação para enfrentamento dos problemas educacionais do país. A ideia de um plano relativo à educação remonta a 1932, e a primeira versão foi efetivada apenas em 1962, alterada e revisada diversas vezes nos anos seguintes, até a homologação de uma segunda versão em 2001, com abrangência prevista de 10 anos. 
Uma nova versão estava prevista para o período 2011-2020, e o plano foi aprovado somente em 2014, fato que indica os interesses conflitantes envolvidos na questão. A edição 20012010 foi considerada como não efetiva, por possuir diversas metas de difícil mensuração, pela não inclusão de sanções, pelo não cumprimento dessas metas pelos envolvidos e pela ausência de mecanismos de financiamento. Isto também fez com que não se constituísse como diretriz para políticas, planejamento e gestão da educação (DOURADO, 2010). A versão de 2014 nasceu com a intenção de ser um plano decenal com ações de acompanhamento a cada 2 anos.

O PNE 2014-2024 (BRASIL, 2014) apresenta 20 metas, divididas em indicadores, que afetam direta ou indiretamente a EPT. A meta 11 é específica e estabelece triplicar as matrículas em cursos técnicos durante a vigência do programa (BRASIL, 2014). Segundo o documento PNE - Linha de base (MEC.INEP, 2015), a Educação Profissional incluía 1.602 .946 matrículas (em 2013), e a meta para 2024 é indicada como 4.808.838. A plataforma online Observatório do PNE, organizado e mantido por diversas organizações (OBSERVATÓRIO, 2016) apresenta números um pouco diferentes: 1.741 .528 matrículas referidas a 2014 e meta de 5.224.584. Como o valor apresentado como base pelo Observatório do PNE é igual ao que serviu de base para a elaboração do gráfico 2 acima, obtido das sinopses estatísticas do INEP, pode-se supor que o documento Linha de base considera outros cursos de formação profissional, tais como normal/magistério e EJA integrado à educação profissional.

Outro indicador da meta 11 requer que pelo menos $50 \%$ da expansão das matrículas ocorra no setor público. Segundo o documento Linha de base, o setor público era responsável por 56,2\% das matrículas em 2013 , valor assumido como referência, devendo chegar a um total um pouco superior a 2,5 milhões de matrículas em 2024 . O valor obtido da sinopse estatística de 2015 , considerando somente cursos técnicos, é da ordem de $54,5 \%$. Comparando com os valores de 2013 , há pequena diferença, decorrente das variantes de agregação comentadas acima, confirmando que o setor público tem ofertado um pouco mais de $50 \%$ das matrículas nos últimos anos. As estratégias incluem, entre outras, expansão da Rede Federal EPT, expansão dos sistemas estaduais e da EaD, cursos gratuitos no Sistema S, financiamento para cursos nas instituições privadas e implantação de um sistema de avaliação. A meta 11 do PNE inclui, também, uma proposta de ampliar a taxa de conclusão dos cursos técnicos para 90\%, a qual parece ser significativamente difícil de ser alcançada, 
pois, apesar dos dados disponíveis serem poucos e discutíveis, estão bem abaixo dessa meta. Dados apresentados por Silva (2013) indicam que, nos IF, a taxa de conclusão é bastante variável por região, instituição, curso, e período de implantação, indo de $20 \%$ a $60 \%$ nas melhores situações. Esta meta subverte a questão do mérito, com risco de levar à facilitação da aprovação, aligeiramento e redução da formação, o que implica na qualidade do processo, no perfil do egresso e no descrédito do sistema. Requer, portanto, aprofundamento e, se mantida, cuidados para redução do risco.

Entre as estratégias previstas no PNE, especificamente na meta 11, podem ser destacadas as seguintes, pela adequação aos objetivos e necessidades da EPT:

- Expandir a Rede Federal EPT, composta principalmente pelos Institutos Federais, completando as condições para oferta de vagas prioritariamente de cursos integrados, evitando a dissociação da formação geral da formação para o trabalho;

- Ampliar os sistemas estaduais EPT, concentrando, também, em cursos integrados, através de incentivos aos Estados;

- Manter a gratuidade de cursos ofertados pelo Sistema S e ampliar o financiamento para instituições privadas;

- Implantar um sistema de avaliação da formação profissional técnica, que ainda não existe formalmente, e que representa uma necessidade fundamental, pois a avaliação permite acompanhar o desenvolvimento dos cursos, indicando ações de correção e ajuste ao longo do processo. Sem um sistema efetivo de avaliação, todas as metas e estratégias tem seu acompanhamento prejudicado, reduzido, muitas vezes, a opiniões sem base que as sustentem.

Outras metas do PNE, embora não específicas para a EPT, também a afetam. A meta 12 trata da Educação Superior, com previsão para incluir, neste nível, 33\% dos jovens de 18 a 24 anos (taxa líquida de matrícula), e quantidade total de matrículas que corresponda a $50 \%$ do total de jovens na mesma faixa etária que, em 2014 , estão em $17,7 \%$ e 34,2\% respectivamente, com $40 \%$ da expansão no setor público, que em 2014 foi de 5,5\% (OBSERVATÓRIO, 2016). Pelo documento Linha de base (MEC.INEP, 2015), as taxas líquida e bruta de matrículas, em 2013, foram de $20,2 \%$ e $30,3 \%$, enquanto a expansão no setor 
público foi da ordem de 23,3\% na década 2004 a 2013, o que indica o grande desafio que inclui, também, os cursos de tecnologia, e requer, inclusive, análises específicas, pois a implementação dessa meta envolve direcionar o crescimento em modalidades e cursos segundo prioridades.

A meta 15 pretende que todos os professores da Educação Básica tenham formação superior (56,2\% em 2014), e que todos os professores do Ensino Médio tenham licenciatura na área em que atuam (59,2\% em 2014). A meta 16, por sua vez, pretende que $50 \%$ dos professores tenham formação em nível de pós-graduação (31,4\% em 2014). Os dados do documento Linha de base (MEC.INEP, 2015), relativos a 2013 são de 50,5\%, 55,7\% e 30,2\%, respectivamente. Os dados do Observatório PNE (2016) relativos a 2014 são 56,2\%, $59,2 \%$ e $31,4 \%$, respectivamente, indicando diferenças que podem ser atribuídas à variação de um ano para outro e agregações diferenciadas. Assim sendo, estes indicadores representam, também, um grande desafio, que afeta a EPT, possivelmente mais do que outros tipos de cursos, pois os professores desse sistema precisam de formação nas áreas de atuação. Além disso, estes professores possuem, em sua maioria, formação profissional e pouca ou nenhuma formação pedagógica sistemática, o que por si só representa um elemento adicional a requerer incentivos, indicando a oportunidade de formação docente em nível de pós-graduação.

Em termos de financiamento, a meta 20 prevê a aplicação de 7\% do Produto Nacional Bruto - PIB até 2019 e 10\% até 2024, e o documento Linha de Base (2015) indica um percentual de 6,2\% em 2013; o Observatório PNE não apresenta um valor, alegando dificuldade na composição dos dados disponíveis.

\subsection{O CENÁRIO DA EaD NA EPT}

Embora a tendência da educação seja superar a dicotomia entre as modalidades presencial e a distância, conforme já indicava Lévy (1999), superando a adjetivação, no momento atual, a distinção ainda se faz necessária, considerando que os cursos são classificados conforme a modalidade, o que inclui os dados estatísticos disponíveis. No caso da EPT, os dados do INEP para a Educação Básica não são separados por modalidade. Para a Educação Superior isso já vem ocorrendo, embora persistam dificuldades de agregação a 
partir das sinopses. Assim, embora conste o total de matrículas em cursos de graduação EaD, não consta sua separação por nível acadêmico. Relações entre a organização acadêmica e categoria administrativa constam no quadro 6, que indica a alta concentração de matrículas da modalidade nas instituições privadas, e participação do setor público em torno de apenas 10\%. Ressalta-se a pequena participação da Rede Federal EPT, que pode e deve ser ampliada.

Quadro 6 - Percentual de matrículas em EaD nos cursos de graduação - 2014

\begin{tabular}{|c|c|c|c|c|c|}
\hline & Universidades & $\begin{array}{c}\text { Centros } \\
\text { universitários }\end{array}$ & Faculdades & IF CEFET & Total \\
\hline Federal & $87.808(9,1 \%)$ & & & 8.674 & $96.482(7,2 \%)$ \\
\hline Estadual & $39.181(4,1 \%)$ & & & & $39.181(2,9 \%)$ \\
\hline Municipal & $3.710(0,4 \%)$ & & & & $3.710(0,3 \%)$ \\
\hline Total público & $130.699(13,6 \%)$ & & & 8.674 & $139.373(10,4 \%)$ \\
\hline Privada & $831.359(86,4 \%)$ & 330.035 & 41.075 & & $1.202 .469(89,6 \%)$ \\
\hline Total & $962.058(71,7 \%)$ & $\begin{array}{c}330.035 \\
(24,6 \%)\end{array}$ & $\begin{array}{c}41.075 \\
(3,0 \%)\end{array}$ & $\begin{array}{c}8.674 \\
(0,6 \%)\end{array}$ & $1.341 .842(100 \%)$ \\
\hline
\end{tabular}

Fonte: Compilado pelos autores a partir da Sinopse Estatística (INEP, 2014b).

No caso específico de formação técnica a distância, existem poucos dados quantitativos. As sinopses estatísticas do INEP não têm diferenciado cursos presenciais e a distância, o que restringe as comparações entre as modalidades. O Censo 2014 da Associação Brasileira de Educação a Distância (ABED, 2015) indica 155 cursos técnicos em um universo de 1840 cursos a distância, representando $8,42 \%$ dos cursos e $11,57 \%$ das matrículas.

Dos poucos dados específicos sobre cursos técnicos a distância, que são ofertados pelo programa Rede eTec Brasil, uma das fontes são os Relatórios de Gestão da SETEC-MEC. O mais recente disponível aponta as metas e vagas ofertadas pela Rede eTec Brasil (MEC.SETEC, 2015), e preveem 250 mil matrículas em 2014 em cursos técnicos subsequentes a distância.

\subsection{CONSIDERAÇÕES SOBRE OS DADOS DA EPT}

As considerações acima permitem apontar aspectos relevantes sobre as perspectivas da EPT no Brasil. Em primeiro lugar pode-se citar que a dicotomia relativa ao ensino de caráter propedêutico separado do ensino profissional persiste, principalmente na 
forma dos cursos técnicos dos tipos integrado e subsequente, e requer acompanhamento para mantê-los dentro de parâmetros pré-estabelecidos e considerados aceitáveis pelos atores e gestores das políticas públicas.

Em relação à meta 11, especificamente, observa-se que ela pode ser atingida, ao se considerar o crescimento das matrículas nos cursos de formação profissional nos últimos anos. No entanto, como a meta não detalha o tipo de curso, a implantação dessa política pública pode ser direcionada fortemente para cursos subsequentes, de menor duração e custo reduzido, o que requer cuidados no processo de implementação desta meta.

A ampliação de matrículas é uma fase inicial que deve, na sequência, aumentar a quantidade de concluintes, demandando formas de reduzir a evasão e a retenção, problemas que afetam todos os cursos.

O cumprimento da meta 11 exige reforço e ampliação do sistema EPT brasileiro, com apoio efetivo aos IF, sistemas estaduais e instituições privadas, para cumprir com o indicador de ampliação do sistema público.

Além disso, se os desafios quantitativos são significativos, requerendo políticas de incentivo, com implantação e implementação coerentes, sistemáticas e organizadas, os desafios qualitativos são ainda maiores, decorrentes da conhecida precariedade da formação de nível médio (FRIGOTTO; CIAVATTA; RAMOS, 2005).

A forma de melhorar a qualidade requer sistemas de avaliação efetivos, pois não existe, atualmente, um sistema de avaliação do ensino técnico. O cumprimento das metas quantitativas e qualitativas e das finalidades expressas nos documentos relativos à EPT também apontam a questão da avaliação como ponto chave a ser considerado no estudo.

Observa-se, também, que o sistema EPT precisa evoluir de forma a seguir pela pós-graduação, tanto em especializações como mestrado e doutorado. Neste sentido, pesquisas são fundamentais para aprofundar, acompanhar e indicar aprimoramentos no processo.

\section{CONCLUSÕES}

Este texto buscou contextualizar a situação da EPT no Brasil, a partir da comparação entre dados fornecidos pelo INEP e metas do PNE 2014-2024. 
Verificou-se que o cenário atual representa um grande desafio para a EPT brasileira, que precisa evoluir em termos quantitativos e qualitativos. Os dados apresentados apontam ações que têm maior viabilidade de serem executadas, por seguirem tendências observadas na evolução recente do processo. Assim, cursos técnicos devem ser ampliados, tanto no tipo integrado como no subsequente, principalmente no sistema público, que já representa boa participação nos cursos do tipo integrado, e também no sistema privado, que pode e deve participar da melhoria das condições de oferta.

No caso dos cursos de tecnologia, que tem crescido a taxas mais elevadas que bacharelados e licenciaturas, os desafios incluem aumentar ainda mais essas taxas para responder as necessidades educacionais. Nesse processo, a Rede Federal EPT, sistemas estaduais e educação a distância têm condições de ser elementos-chave para a ampliação.

O processo requer, ainda, um sistema de avaliação efetivo que responda às necessidades de informações para subsidiar tanto o acompanhamento como a melhoria dos processos. A formação de professores requer, também, ampliação da oferta de cursos de especialização, bem como de mestrado e doutorado, de forma a constituir elementos de pesquisa aprofundada que discuta e oriente a evolução da EPT.

\section{REFERÊNCIAS}

ABED. Censo ABED da Educação a Distância 2014/2015. Disponível em: < http://www.abed.org.br/site/pt/midiateca/censo ead/> Acesso em: ago./2016.

BRASIL. Decreto 2.208 de 17 de abril de 1997. Regulamenta a Educação Profissional. Brasília. Diário Oficial da União, Brasília, 17 de abril de 1997.

BRASIL. Decreto 5.154 de 23 de julho de 2004. Regulamenta a educação profissional. Brasília. Diário Oficial da União, Brasília, 23 de julho de 2004.

BRASIL. Decreto-Lei 4.040 de 22 de janeiro de 1942. Criação do Serviço Nacional de Aprendizagem Industrial. Rio de Janeiro. Diário Oficial da União, Brasília, 22 de janeiro de 1942.

BRASIL. Lei 11.748 de 16 de julho de 2008. Altera dispositivos da LDBE. Brasília. Diário Oficial da União, Brasília, 16 de julho de 2008.

Brasil. Lei 13.095 de 25 de julho de 2014. Aprova o Plano Nacional de Educação. Brasília. Diário Oficial da União, Brasília, 25 de julho de 2014. 
BRASIL. Lei 4.024 de 20 de dezembro de 1961. Lei de Diretrizes e Bases da Educação Nacional. Rio de Janeiro. Diário Oficial da União, Brasília, 20 de dezembro de 1961.

CUNHA, Luiz Antonio. O ensino industrial-manufatureiro no Brasil. Revista Brasileira de Educação, n. 14, 2000.

DOURADO, Luiz Fernando. (2010). Avaliação do Plano NacionaL de Educação 2001-2009: questões estruturais e conjunturais de uma política. Educação e Sociedade, Campinas, v.31, n.122.

FRIGOTTO, Gaudêncio; CIAVATTA, Maria; RAMOS, Marise. Ensino médio integrado: concepção e contradições. São Paulo: Cortez, 2005.

INEP. Sinopse Estatística da Educação Básica 2008. Disponível em: <http://portal.inep.gov.br/basica-censo-escolar-sinopse-sinopse> Acesso em: ago./2016.

INEP. Sinopse Estatística da Educação Básica 2009. Disponível em: <http://portal.inep.gov.br/basica-censo-escolar-sinopse-sinopse> Acesso em: ago./2016.

INEP. Sinopse Estatística da Educação Básica 2010. Disponível em: <http://portal.inep.gov.br/basica-censo-escolar-sinopse-sinopse> Acesso em: ago./2016.

INEP. Sinopse Estatística da Educação Básica 2011. Disponível em: <http://portal.inep.gov.br/basica-censo-escolar-sinopse-sinopse> Acesso em: ago./2016.

INEP. Sinopse Estatística da Educação Básica 2012. Disponível em: <http://portal.inep.gov.br/basica-censo-escolar-sinopse-sinopse> Acesso em: ago./2016.

INEP. Sinopse Estatística da Educação Básica 2013. Disponível em: <http://portal.inep.gov.br/basica-censo-escolar-sinopse-sinopse> Acesso em: ago./2016.

INEP. Sinopse Estatística da Educação Básica 2014 (a). Disponível em: <http://portal.inep.gov.br/basica-censo-escolar-sinopse-sinopse> Acesso em: ago./2016.

INEP. Sinopse Estatística da Educação Básica 2015. Disponível em: <http://portal.inep.gov.br/basica-censo-escolar-sinopse-sinopse> Acesso em: ago./2016.

INEP. Sinopse Estatística da Educação Superior 2014 (b). Disponível em:

<http://portal.inep.gov.br/superior-censosuperior-sinopse> Acesso em: ago./2016.

KUENZER, Acacia Zenaida. Ensino médio e profissional: as políticas do Estado neoliberal (4aㅡ ed.) São Paulo: Cortez, 2007.

LÉVY, Pierre. Cibercultura. São Paulo: Ed 34, 1999.

MEC.INEP. Censo da Educação Superior 2013: resumo técnico. Brasília: INEP, 2013. 
MEC.INEP. Plano Nacional de Educação PNE 2014-2024: Linha de base. Brasília: INEP, 2015.

MEC. SETEC. Prestação de contas ordinária anual - Relatório de Gestão Consolidado. Ministério da Educação. Exercício 2014. Brasília, 2015.

NASCIMENTO, Osvaldo Ferreira do. Cem anos de ensino profissional no Brasil. Curitiba: Ibepex, 2007.

OBSERVATÓRIO DO PNE. Plataforma online. Disponível em: $<$ http://www.observatoriodopne.org.br/metas-pne/11-educacao-profissional > Acesso em: ago./2016.

PEREIRA, Samara Cristina Silva; PASSOS, Guiomar de Oliveira. As políticas para a educação profissional técnica de nível médio: dois projetos em disputa. In: $V$ Jornada Internacional de Políticas Públicas. São Luiz: 2011.

RAMIREZ, Omar. Evaluacion comparativa de programas de formacion ocupacional. 2002. (Tese de doutorado). Universid autonoma de Barcelona, Bracelona, 2002.

SILVA, Tadeu Lucena. Baixa taxa de conclusão dos cursos técnicos da Rede Federal EPT: uma proposta de intervenção. Dissertação de mestrado. Universidade Federal de Juiz de Fora. Juiz de Fora: 2013.

STANFORD. Stanford Encyclopedia of Philosophy. 2003. Disponível em: <plato.stanford.edu>. Acesso em: jul./2014.

UNESCO. Clasificación Internacional Normalizada de la Educación - CINE, 2016.

RECEBIDO EM 15 DE AGOSTO DE 2016.

APROVADO EM 31 DE OUTUBRO DE 2016. 